\title{
PEMBENTUKAN KARAKTER PESERTA DIDIK MELALUI KEPANDUAN HIZBUL WATHAN (Studi Terhadap Implementasi Manajemen Kurikulum Pengenal Tingkat Purwa Kepanduan Hizbul Wathan di SMP Muhammadiyah se Kulon Progo)
}

\author{
Raden Wisnu Broto \\ Program PascaSarjana \\ Universitas Muhammadiyah Yogyakarta \\ E-mail: brtwisnu72@gmail.com
}

\begin{abstract}
Abstrak
Penelitian ini bertujuan untuk : (1) mengetahui mengapa terdapat perbedaan dalam memahami kurikulum pengenal tingkat purwa kepanduan Hizbul Wathan di SMP Muhammadiyah se Kulon Progo; (2) mengetahui implementasi manajemen kurikulum pengenal tingkat purwa kepanduan Hizbul Wathan dalam membentuk karakter peserta didik SMP Muhammadiyah se Kulon Progo; (3) bagaimana efektifitas pembentukan karakter peserta didik pengenal tingkat purwa kepanduan Hizbul Wathan di SMP Muhammadiyah se Kulon Progo yang berkaitan dengan karakter peserta didik.Jenis penelitian yang penulis gunakan adalah penelitian deskriptif kualitatif. Lokasi penelitian adalah SMP Muhammadiyah se Kulon Progo di bawah naungan Pimpinan Daerah Muhammadiyah Kabupaten Kulon Progo. Hasil penelitian: (1) Perbedaan dalam memahami kurikulum pengenal tingkat Purwa kepanduan Hizbul Wathan di SMP Muhammadiyah se Kulon Progo. (2) Implementasi manajemen kurikulum pengenal tingkat purwa kepanduan Hizbul Wathan dalam membentuk karakter peserta didik kelas tujuh SMP Muhammadiyah se Kulon Progo disusun berdasarkan penjabaran visi misi kepanduan Hizbul Wathan di sekolah masing-masing. (3) Pembentukan karakter peserta didik pengenal tingkat purwa kepanduan Hizbul Wathan di SMP Muhammadiyah se Kulon Progo berjalan efektif.

Kata kunci: pembentukan karakter, peserta didik, kepanduan Hizbul Wathan, Implementasi kurikulum
\end{abstract}

\begin{abstract}
This study aims to: (1) find out why there are differences in understanding the level of learning curriculum of the level of scouting at Hizbul Wathan at Muhammadiyah Middle School in Kulon Progo; (2) to find out the implementation of the level-level introduction of curriculum management in Hizbul Wathan's scout in shaping the character of Muhammadiyah junior high school students in Kulon Progo; (3) how is the effectiveness of character formation of students who are familiar with the level of scouting at Hizbul Wathan at Muhammadiyah Middle School in Kulon Progo that is related to the character of students. The type of research I use is qualitative descriptive research. The location of the study was Muhammadiyah Middle School in Kulon Progo under the auspices of the Muhammadiyah Regional Head of Kulon Progo Regency. The results of the study: (1) Differences in understanding the identification curriculum of Purwa's level scouted by Hizbul Wathan at Muhammadiyah Middle School in Kulon Progo.

(2) The implementation of the level-level introduction of curriculum management in Hizbul Wathan scouting in forming the character of seventh graders of Muhammadiyah Se Kulon Progo Middle School was compiled based on the Hizbul Wathan scouting vision and mission in their respective schools. (3) The formation of the character of students who are familiar with the level of the scouting of Hizbul Wathan at the Muhammadiyah Middle School in Kulon Progo runs effectively.

Keywords: character building, students, scouting Hizbul Wathan, curriculum implementation
\end{abstract}

\section{Info Artikel}

Diterima Januari 2019, disetujui Februari 2019, diterbitkan Juni 2019 


\section{PENDAHULUAN}

Pendidikan karakter sangat penting bagi seluruh umat manusia, termasuk peserta didik kelas tujuh/pengenal tingkat purwa SMP Muhammadiyah se Kulon Progo. Karena sangat pentingnya pendidikan karakter pada peserta didik ini, maka Pemerintah Republik Indonesia menuangkannya dalam Undang-Undang Nomor 20 Tahun 2003 tentang Sistem Pendidikan Nasional pasal 3. Adapun Undang-Undang Nomor 20 Tahun 2003 tentang Sistem Pendidikan Nasional pasal 3 menegaskan bahwa pendidikan nasional berfungsi mengembangkan kemampuan dan membentuk watak serta peradaban bangsa yang bermartabat dalam rangka mencerdaskan kehidupan bangsa, bertujuan untuk berkembangnya potensi peserta didik agar menjadi manusia yang beriman dan bertakwa kepada Tuhan Yang Maha Esa, berakhlak mulia, sehat, berilmu, cakap, kreatif, mandiri, dan menjadi warga negara yang demokratis serta bertanggung jawab.

Salah satu organisasi yang berkomitmen membentuk karakter adalah kepanduan Hizbul Wathan. Sebagai salah satu gerakan kepanduan yang bergerak dalam pendidikan nonformal, kepanduan Hizbul Wathan mempunyai kewajiban untuk membantu pemerintah dan masyarakat dalam membangun karakter generasi muda. Gerakan kepanduan Hizbul Wathan adalah gerakan kepanduan Islami. Pendidikan berlaku bagi anggota muda dan anggota dewasa. Anggota kepanduan Hizbul Wathan dimulai sejak umur enam tahun sampai akhir hayat. Hakekat pendidikan Hizbul Wathan adalah pembentukan karakter. Intinya adalah tauhid dan akhlak mulia, yang dipandu dengan Kode Kehormatan yaitu "Janji dan Undang-Undang Pandu”. Sebagai organisasi yang mempunyai payung besar Muhammadiyah, maka gerakan kepanduan Hizbul Wathan harus siap sedia menjadi kader yang istiqomah, yang siap melaksanakan perintahnya dengan ikhlas. Tentu saja kepanduan Hizbul Wathan harus membina para anggotanya yang memiliki sifat benar, amanah, fathonah, dan tablig

Di dalam kepanduan Hizbul Wathan ada persoalan salah satunya ketidaksamaan dalam memahami kurikulum. Kurikulum merupakan program pendidikan yang disediakan oleh lembaga pendidikan (sekolah) bagi peserta didik, sehingga pengertian kurikulum adalah segala pengalaman pendidikan yang diberikan oleh sekolah kepada seluruh anak didiknya, baik dilakukan di dalam sekolah maupun di luar sekolah. Materi dalam kurikulum disesuaikan dengan situasi, kondisi, atau keadaan daerah dimana Pandu Athfal, Pengenal, dan Penghela berada. Satu daerah berbeda dengan daerah lain 
di Indonesia. Daerah pegunungan akan berlainan keadaannya dengan daerah dekat pantai, sehingga pelatih harus mampu memvariasikan materi dengan keadaan daerah.

Mengapa kurikulum yang dibuat sama bisa berbeda dalam memahami dan menerapkannya sehingga menghasilkan karakter peserta didik yang berbeda-beda. Oleh karena itu perlu adanya studi terhadap implementasi manajemen kurikulum kepanduan Hizbul Wathan khususnya untuk pengenal tingkat purwa. Perlu juga dikaji lebih mendalam dalam penerapannya di sekolah Muhammadiyah khususnya di SMP Muhammadiyah se Kulon Progo mengapa terdapat perbedaan dalam memahami kurikulum pengenal tingkat purwa kepanduan Hizbul Wathan di SMP Muhammadiyah se Kulon Progo.

Bagaimana implementasi kurikulum pengenal tingkat purwa kepanduan Hizbul Wathan selama ini dalam membentuk karakter peserta didik kelas tujuh SMP Muhammadiyah se Kulon Progo. Bagaimana efektifitas pembentukan karakter peserta didik pengenal tingkat purwa kepanduan Hizbul Wathan di SMP Muhammadiyah se Kulon Progo. Berdasarkan uraian tersebut di atas penelitian ini bertujuan untuk mengetahui mengapa terdapat perbedaan dalam memahami kurikulum pengenal tingkat Purwa kepanduan Hizbul Wathan di SMP Muhammadiyah se Kulon Progo, bagaimana implementasi manajemen kurikulum, dan bagaimana efektifitas pembentukan karakter peserta didik pengenal tingkat purwa kepanduan Hizbul Wathan di SMP Muhammadiyah se Kulon Progo yang berkaitan dengan karakter peserta didik. Mengapa kurikulum tingkat purwa kepanduan Hizbul Wathan sama bisa menghasilkan karakter yang berbeda-beda terhadap pengenal tingkat purwa/peserta didik kelas tujuh SMP Muhammadiyah se Kulon Progo.

\section{KAJIAN PUSTAKA}

\section{Karakter}

Karakter merupakan watak atau tabiat setiap orang yang dimiliki sejak lahir. Hal inilah yang membedakan setiap manusia termasuk peserta didik pada jenjang SMP. Bila ditelusuri asal kata karakter dari bahasa Latin "Kharakter", "Kharassein", "kharax", Yunani character, dari charassein yang berarti membuat tajam, membuat dalam. Dalam Kamus Poerwadarminta, karakter diartikan sebagai tabiat, watak, sifat-sifat kejiwaan, akhlak atau budi pekerti yang membedakan seseorang dengan yang lain. Ciri pribadi 
yang meliputi hal-hal seperti perilaku, kebiasaan, kemampuan, kecenderungan, potensi, nilai-nilai dan pola-pola pemikiran.

\section{Kepanduan Hizbul Wathan}

Gerakan Kepanduan Hizbul Wathan adalah salah satu organisasi otonom Muhammadiyah, yang dinyatakan sebagai salah satu wadah perkaderan yang efektif. Obyek perkaderannya adalah anak-anak, remaja, dan pemuda, dengan menggunakan prinsip dasar dan metode kepanduan. Sebagai organisasi otonom, gerakan kepanduan Hizbul Wathan mempunyai visi percepatan peningkatan pertumbuhan dan pengembangan organisasi kepanduan yang berkemajuan, serta mengemban misi Muhammadiyah dalam pendidikan anak, remaja, dan pemuda, sehingga mereka menjadi muslim yang sebenar-benarnya, dan siap menjadi kader persyarikatan, umat, dan bangsa. Sistem pendidikan kepanduan Hizbul Wathan adalah di luar keluarga dan sekolah untuk anak, remaja, dan pemuda dilakukan di alam terbuka dengan metode yang menarik, menyenangkan, dan menantang. Kegiatan pendidikan kepanduan sifatnya mengisi kekosongan kegiatan di rumah dan di sekolah. Dalam kepanduan Hizbul Wathan diutamakan pembinaan akidah, akhlak, ibadah, dan muamalah duniawiyah dalam bentuk kegiatan praktis yang menarik, menyenangkan, menantang, dan diutamakan di alam terbuka.

\section{Manajemen Kurikulum}

Manajemen kurikulum menurut pandangan Husaini Usman adalah seni dan ilmu mengelola sumber daya pendidikan untuk mewujudkan suasana belajar dan proses pembelajaran agar peserta didik secara aktif mengembangkan potensi dirinya untuk memiliki kekuatan spiritual keagamaan, pengendalian diri, kepribadian, kecerdasan, akhlak mulia, serta ketrampilan yang diperlukan dirinya, masyarakat, bangsa, dan Negara. Menurut Suharsimi Arikunto manajemen kurikulum adalah segenap proses usaha bersama untuk memperlancar pencapaian tujuan pengajaran dengan titik berat pada usaha, meningkatkan interaksi belajar-mengajar. 


\section{Efektifitas Organisasi}

Dalam memaknai efektifitas setiap orang member arti yang berbeda, sesuai sudut pandang, dan kepentingan masing-masing. Hal tersebut diakui oleh Chung dan Maginson, "Efektivenes means different to different people." Dalam Kamus Besar Bahasa Indonesia dikemukakan bahwa efektifitas berarti ada efeknya (akibatnya, pengaruhnya, kesannya), manjur atau mujarab, dapat membawa hasil. Jadi efektifitas adalah adanya kesesuaian antara orang yang melaksanakan tugas dengan sasaran yang dituju. Efektifitas adalah bagaimana suatu organisasi berhasil mendapatkan dan memanfaatkan sumber daya dalam usaha mewujudkan tujuan operasional.

Berdasarkan pengertian di atas, dapat dikemukakan bahwa efektifitas berkaitan dengan terlaksananya semua tugas pokok, tercapainya tujuan, ketepatan waktu, dan adanya partisipasi aktif dari anggota. Masalah efektifitas biasanya berkaitan erat dengan perbandingan antara tingkat pencapaian tujuan dengan rencana yang telah disusun sebelumnya, atau perbandingan hasil nyata dengan hasil yang direncanakan. Berdasarkan teori sistem, kriteria efektifitas harus mencerminkan keseluruhan siklus input-proses-output, tidak hanya output atau hasil.

\section{METODE PENELITIAN}

Penelitian yang akan dilakukan termasuk dalam kategori penelitian lapangan (field research). Adapun jenis penelitian lapangan yang digunakan adalah penelitian kualitatif, tempat penelitian tesis ini di SMP Muhammadiyah di bawah naungan Pimpinan Daerah Muhammadiyah Kabupaten Kulon Progo, waktu penelitian April 2018-Mei 2018.

\section{Sampel penelitian}

Sampel adalah sebagian dari subjek penelitian.8 yaitu sebagian dari SMP Muhammadiyah se Kulon Progo. Sistem yang digunakan yakni sistem sampel purposive sampling atau judgement sampling. Purpose sampling adalah teknik penentuan sampel dengan berdasarkan kriteria- kriteria atau pertimbangan tertentu.9 Kriterianya yakni sekolah yang secara nyata melakukan kegiatan kepanduan Hizbul Wathan pada tataran pengenal tingkat purwa di SMP Muhammadiyah se Kulon Progo dengan kategori/kriteria satu SMP Muhammadiyah yang dianggap maju di dalam kegiatan 
kepanduan Hizbul Wathan (SMP Muhammadiyah 2 Wates), satu SMP Muhammadiyah yang dianggap sedang di dalam kegiatan kepanduan Hizbul Wathan (SMP Muhammadiyah 3 Kokap), dan satu SMPMuhammadiyah yang dianggap kurang di dalam kegiatan kepanduan Hizbul Wathan(SMP Muhammadiyah 1 Temon).

\section{Sumber Data}

Narasumber, yaitu sumber data yang akan dimintai keterangan sebagai data melalui wawancara adalah : Pembina Hizbul Wathan, peserta didik kelas tujuh SMP Muhammadiyah se Kulon. Tempat dan aktifitas, adalah sumber data untuk memperoleh data melalui observasi adalah pelaksanaan kegiatan kepanduan Hizbul Wathan di SMP Muhammadiyah se Kulon Progo dengan sekolah lokasi penelitian yaitu SMP Muhammadiyah 2 Wates, SMP Muhammadiyah 3 kokap, dan SMP Muhammadiyah 1 Temon. Dokumen, adalah smber data melalui dokumentasi. Dalam penelitian ini dokumen yang digunakan adalah dokumen kegiatan latihan kepanduan Hizbul Wathan dan jadwal latihan kegiatan kepanduan Hizbul Wathan di sekolah sampel penelitian.

\section{Metode Pengumpulan Data}

Observasi, dokumentasi, wawancara/Interview, dan trianggulasi.

\section{Teknik Analisis Data}

Teknik analisis data kualitatif yang digunakan yakni menggunakan model interaktif menurut Miles dan Huberman. Ada tiga macam kegiatan dalam analisis data kualitatif, yaitu: reduksi data, model data/data display, penarikan/ verifikasi kesimpulan.10

\section{HASIL PENELITIAN DAN PEMBAHASAN}

\section{Perbedaan dalam memahami kurikulum pengenal tingkat Purwa kepanduan}

\section{Hizbul Wathan.}

Materi dalam kurikulum disesuaikan dengan situasi, kondisi, atau keadaan daerah di mana pandu athfal, pengenal, dan penghela berada. Satu daerah berbeda dengan daerah yang lain di Indonesia. Daerah pegunungan akan berlainan keadaannya dengan daerah dekat pantai sehingga pelatih harus mampu memvariasikan materi dengan 
keadaan daerah. Hal yang paling mendasar mengapa terjadi perbedaan dalam memahami kurikulum pengenal tingkat purwa kepanduan Hizbul Wathan di SMP Muhammadiyah se Kulon Progo adalah dengan adanya pernyataan bahwa materi dalam kurikulum disesuaikan dengan situasi, kondisi, atau keadaan daerah di mana pandu athfal, pengenal, dan penghela berada.

Kurikulum yang ada dari pusat seharusnya bisa sampai ke tingkat qobilah se Indonesia termasuk sampai ke Kulon Progo, akan tetapi hal tersebut tidak terjadi. Kurikulum sama se Indonesia tetapi ada perbedaan dalam memahami kurikulum pengenal tingkat purwa. Dari hasil penelitian diperoleh bahwa perbedaan dalam memahami kurikulum pengenal tingkat purwa kepanduan Hizbul Wathan di SMP Muhammadiyah se Kulon Progo disebabkan oleh : 1). Letak geografis masing-masing daerah sehingga kurikulum yang ada menyesuaikan dengan situasi dan kondisi daerah itu dimana kurikulum di daerah pegunungan berbeda dengan daerah di pinggiran, kurikulum di daerah perkotaan berbeda dengan daerah di pedesaan. 2). Kurangnya sosialisasi dari kwartir pusat ke kwartir wilayah, dari kwartir wilayah ke kwartir daerah, dari kwartir daerah ke kwartir cabang dan qobilah sehingga menimbulkan pertanyaan kurikulum yang mana yang dipakai di dalam kegiatan kepanduan Hizbul Wathan khususnya kurikulum pengenal tingkat purwa. 3). Ketidaktahuan kurikulum yang dipakai di dalam kegiatan kepanduan Hizbul Wathan sehingga pembina memberikan kurikulum menurut kurikulum sekolahnya masing-masing bahkan ada yang mengacu pada kurikulum terdahulu dari sekolah tersebut. 4). Pembina yang cenderung pasif/kurang aktif di dalam mencari informasi termasuk kurikulum pengenal tingkat purwa kepanduan Hizbul Wathan di sekolah Muhammadiyah se Kulon Progo.

\section{Implementasi manajemen kurikulum pengenal tingkat purwa kepanduan Hizbul} Wathan.

Dari hasil observasi di SMP Muhammadiyah se Kulon Progo dengan metode sampling diperoleh data bahwa implementasi manajemen kurikulum pengenal tingkat purwa kepanduan Hizbul Wathan dalam membentuk karakter peserta didik kelas tujuh SMP Muhammadiyah se Kulon Progo disusun berdasarkan penjabaran visi misi kepanduan Hizbul Wathan dan disusun oleh masing-masing sekolah dengan mengacu pada materi yang memuat pendidikan karakter dalam materi/kegiatannya tanpa 
mengikuti kurikulum dari kwartir pusat gerakan kepanduan Hizbul Wathan. Masingmasing sekolah menyusun kurikulumnya sendiri dengan mengacu pada kurikulum/materi tahun sebelumnya karena tidak ada kontrol dari kwartir cabang, kwartir daerah, kwartir wilayah, bahkan kwartir pusat di dalam penyusunan kurikulum yang digunakan dalam kegiatan kepanduan Hizbul Wathan pengenal tingkat purwa. Kurikulum yang ada pada masing-masing qobilah disusun berdasarkan keinginan qobilah itu sendiri dengan memperhatikan materi kurikulum yang mengandung pembentukan karakter.

\section{Efektifitas pembentukan karakter peserta didik pengenal tingkat purwa kepanduan Hizbul Wathan.}

Untuk memperoleh data tentang efektifitas pembentukan karakter peserta didik pengenal tingkat purwa kepanduan Hizbul Wathan di SMP Muhammadiyah se Kulon Progo peneliti melakukan observasi langsung terhadap proses kegiatan kepanduan Hizbul Wathan pada sekolah lokasi penelitian yaitu pada SMP Muhammadiyah 2 Wates untuk kategori sekolah yang memiliki kriteria maju, SMP Muhammadiyah 3 Kokap untuk kategori sekolah yang memiliki kriteria sedang, dan SMP Muhammadiyah 1 Temon untuk kategori sekolah yang memiliki kriteria kurang di dalam kegiatan kepanduan Hizbul Wathan. Melakukan wawancara/interview kepada pembina kepanduan Hizbul Wathan beserta peserta didik kepanduan Hizbul Wathan untuk pengenal tingkat purwa dan yang terakhir adalah dokumentasi di sekolah lokasi penelitian.

Sedangkan tolak ukur keberhasilan pembentukan karakter yang tertulis dalam Kriteria Ketuntasan Minimal(KKM) untuk tahun pelajaran 2017/2018 semester genap untuk kegiatan ekstrakurikuler kepanduan Hizbul Wathan kelas VII di sekolah sampel yaitu SMP Muhammadiyah 2 Wates, SMP Muhammadiyah 3 Kokap, dan SMP Muhammadiyah 1 Temon adalah "memuaskan". Hasil memuaskan yang dimaksud adalah jika peserta didik di dalam ujian pengenal tingkat purwa ini memperoleh nilai dalam rentan $\mathrm{A}, \mathrm{B}$, atau $\mathrm{C}$.

Menurut hasil observasi di sekolah lokasi penelitian ditemukan bahwa untuk penilaian tidak mengacu seratus persen pada materi syarat kenaikan tingkat yang ada dan ujian yang ada sebatas apa yang diajarkan dari pembina pada saat pelatihan. Ujian 
yang diberikan kepada pengenal tingkat purwa kepanduan Hizbul Wathan sangat terbatas pada materi selama satu semester yang disampaikan ditambah materi semester sebelumnya. Akan tetapi walaupun penilaian yang ada tidak seratus persen mengacu pada syarat kenaikan tingkat untuk pengenal tingkat purwa, sebagian materi ada yang mendekati sama sehingga hasilnya memuaskan. Dari hasil observasi dan wawancara yang dilakukan bahwa peserta didik kelas tujuh /pengenal tingkat purwa merasakan dan menyatakan bahwa dengan mengikuti kegiatan gerakan kepanduan Hizbul Wathan sikap atau karakter yang dimiliki semua berubah berproses menjadi yang lebih baik.

\section{PENUTUP}

\section{Kesimpulan}

a. Perbedaan dalam memahami kurikulum pengenal tingkat purwa kepanduan Hizbul Wathan di SMP Muhammadiyah se Kulon Progo disebabkan oleh: a. Letak geografis masing-masing daerah. Sehingga kurikulum yang ada menyesuaikan dengan situasi dan kondisi daerah itu. Kurikulum di daerah pegunungan berbeda dengan daerah di pinggiran pantai, kurikulum di daerah perkotaan berbeda dengan daerah di pedesaan.

b. Ketidaktahuan kurikulum yang dipakai di dalam kegiatan kepanduan Hizbul Wathan. Sehingga pembina memberikan kurikulum menurut kurikulum sekolahnya masing-masing. Bahkan ada pembina yang mengacu pada kurikulum terdahulu dari sekolah tersebut.

c. Kurangnya sosialisasi dari kwartir pusat ke kwartir wilayah, dari kwartir wilayah ke kwartir daerah, dari kwartir daerah ke kwartir cabang dan qobilah. Sehingga ini menimbulkan pertanyaan kurikulum mana yang dipakai dalam kegiatan kepanduan Hizbul Wathan, khususnya kurikulum pengenal tingkat purwa. d. Kurang aktifnya qobilah dan pembina kepanduan Hizbul Wathan dalam mencari informasi materi atau kurikulum yang ada.

d. Implementasi manajemen kurikulum pengenal tingkat purwa kepanduan Hizbul Wathan dalam membentuk karakter peserta didik kelas tujuh SMP Muhammadiyah se Kulon Progo disusun berdasarkan penjabaran visi misi kepanduan Hizbul Wathan dan disusun oleh masing-masing sekolah dengan mengacu pada materi yang memuat pendidikan karakter dalam materi/kegiatannya tanpa mengikuti kurikulum 
dari kwartir pusat gerakan kepanduan Hizbul Wathan. Masing-masing sekolah menyusun kurikulumnya sendiri dengan mengacu pada kurikulum/materi tahun sebelumnya karena tidak ada kontrol dari kwartir cabang, kwartir daerah, kwartir wilayah, bahkan kwartir pusat di dalam penyusunan kurikulum yang digunakan dalam kegiatan kepanduan Hizbul Wathan pengenal tingkat purwa. Kurikulum yang ada pada masing-masing qobilah disusun berdasarkan keinginan qobilah itu sendiri dengan memperhatikan materi kurikulum yang mengandung pembentukan karakter.

e. Pembentukan karakter peserta didik pengenal tingkat purwa kepanduan Hizbul Wathan di SMP Muhammadiyah se Kulon Progo berjalan efektif. Hasilnya peserta didik mampu merubah sikap atau kepribadiannya menjadi baik. Hal ini dapat dilihat dalam kesehariannya. Peserta didik di dalam menjalankan kegiatan sehari-hari sadar akan tugas dan tanggung jawab dalam semua hal termasuk taat beribadah. Sedangkan tolak ukur keberhasilan pembentukan karakter tertulis dalam Kriteria Ketuntasan Minimal (KKM) untuk tahun pelajaran 2017/2018 semester genap untuk kegiatan kepanduan Hizbul Wathan kelas VII di sekolah subyek penelitian yaitu SMP Muhammadiyah 2 Wates, SMP Muhammadiyah 3 Kokap, dan SMP Muhammadiyah 1 Temon adalah "memuaskan". Hasil memuaskan yang dimaksud adalah peserta didik di dalam ujian pengenal tingkat purwa ini memperoleh nilai dalam rentan $\mathrm{A}, \mathrm{B}$, dan $\mathrm{C}$ walaupun nilai yang diperoleh tidak mengacu sepenuhnya pada standar syarat kenaikan tingkat pada pengenal tingkat purwa. Dari hasil observasi dan wawancara yang dilakukan bahwa peserta didik kelas tujuh /pengenal tingkat purwa merasakan dan menyatakan bahwa dengan mengikuti kegiatan gerakan kepanduan Hizbul Wathan sikap atau karakter yang dimiliki semua berubah berproses menjadi yang lebih baik.

\section{Saran}

a. Bagi sekolah SMP Muhammadiyah se Kulon Progo agar lebih aktif di dalam kegiatan ekstrakurikuler kepanduan Hizbul Wathan dan mencari informasi yang berkaitan dengan kepanduan Hizbul Wathan sehingga apa yang seharusnya sampai ke qobilah bisa tersampaikan. Dapat menyesuaikan dengan acuan yang telah disahkan oleh kwartir pusat melalui muktamar dan sudah ditanfidzkan. 
b. Bagi pembina kepanduan Hizbul Wathan bisa lebih kreatif dan lebih aktif di dalam menyampaikan materi. Pembina perlu lebih memahami kurikulum yang akan disampaikan pada peserta didik. Selain itu pembina harus benar-benar memahami manajemen kurikulum sehingga manajemen kurikulum benar-benar mengacu pada kurikulum yang ada. Penilaian keberhasilan peserta didik/pengenal tingkat purwa kepanduan Hizbul Wathan sebaiknya mengacu pada syarat kenaikan tingkat untuk pengenal tingkat purwa.

c. Bagi peserta didik pengenal tingkat purwa kepanduan Hizbul Wathan agar lebih memahami karakter atau watak dari diri pribadi masing-masing sehingga apa yang disampaikan dalam kegiatan kepanduan Hizbul Wathan bisa dengan sangat baik diterima dan dilaksanakan dalam kehidupan sehari-hari.

\section{DAFTAR PUSTAKA}

Arikunto, Suharsimi. 2014. Evaluasi Program Pendidikan. Ed.2. cet.5. Jakarta: PT. Bumi Aksara.

Arikunto, Suharsimi. 2006. Prosedur Penelitian Suatu Pendekatan Praktik. Cet 16. Jakarta: PT. Asdi Mahasatya.

Herdiansyah, Haris. 2015. Metodolagi Penelitian Kualitatif untuk Ilmu Psikolois. Salemba. Jakarta: Humanika.

Kwartir Pusat Gerakan Kepanduan Hizbul Wathan. 2007. Kurikulum Gerakan Kepanduan Hizbul Wathan Tingkat Athfal, Pengenal, Penghela, Penuntun. Yogyakarta : Kwartir Pusat Gerakan Kepanduan Hizbul Wathan.

Kwartir Pusat Gerakan Kepanduan Hizbul Wathan. 2008. Jaya Melati II Gerakan Kepanduan Hizbul Wathan. Yogyakarta: Kwartir Pusat Gerakan Kepanduan Hizbul Wathan.

Kwartir Pusat Gerakan Kepanduan Hizbul Wathan. 2016. Pedoman Organisasi Gerakan Kepanduan Hizbul Wathan. Yogyakarta: Kwartir Pusat Gerakan Kepanduan Hizbul Wathan.

Nuh, Muhammad. 2013. Kurikulum 2013 untuk Tingkat Sekolah Menengah Kejuruan/Madrasah Aliyah Kejuruan. Jakarta: PT. Binatama Raya.

Sayuto, Indrati. 2016. Implementasi Sistem Among dalam Pendidikan Karakter Gerakan Kepanduan Hizbul Wathan di SMP Muhammadiyah 2 Wates Kulon Progo Tahun Pelajaran 2015/2016. Tesis. Yogyakarta: Program Pasca Sarjana UST. 
Sugiyono. 2012. Metode Penelitian Kuantitatif Kualitatif dan R\&D. Bandung: Alfabeta.

Usman,Husaini. 2008.Ed. 2. Manajemen: Teori,praktek, dan Riset Pendidikan. Jakarta: Bumi Aksara. 